\title{
Hypothalamo-Sympathetic Modulation of Splenic Natural Killer Cell Activity: An Involvement of Brain Cytokines
}

\author{
Toshihiko Katafuchi* \\ Department of Integrative Physiology, Graduate School of Medical Sciences, Kyushu University, \\ Fukuoka, Japan
}

\begin{abstract}
The sympathetic nervous system is one of the multiple channels that communicate between brain and immune system. In the brain-immune interactions, cytokines produced in the periphery and brain during inflammatory as well as non-

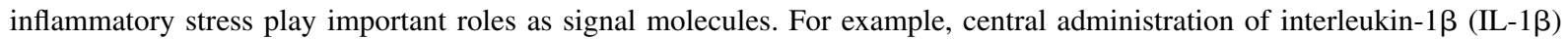
and interferon- $\alpha$ (IFN- $\alpha$ ) suppresses splenic natural killer (NK) cell activity in rats, which is mediated by, at least in part, the sympathetic innervations to the spleen. The central administration of IL-1 $\beta$ and IFN- $\alpha$ increases splenic sympathetic nerve activity, and an electrical stimulation of the nerve results in a suppression of splenic NK cell activity through a $\beta$-adrenergic receptor-mediated process. Furthermore, it has been shown (1) that immobilization (IMB) stress produces an elevation of extracellular concentration of noradrenaline in the spleen, (2) that the IMB-induced reduction of splenic NK activity is partially blocked by splenic denervation, (3) that pretreatment with central injection of neutralizing anti-IL-1 $\beta$ antibody attenuates the IMB-induced NK suppression, and (4) that hypothalamic IL-1 $\beta$ and IFN- $\alpha$ mRNA is increased after $1 \mathrm{hr}$ IMB. These findings, taken together, suggest that IL- $1 \beta$ and IFN- $\alpha$ produced in the brain may be key substances mediating the IMB stress-induced immunosuppression.
\end{abstract}

Keywords: Immobilization, $\beta$-adrenergic receptor, splenic sympathetic nerve, stress-induced immunosuppression

\section{INTRODUCTION}

It is now evident that the central nervous system and the immune system communicate with each other. Among the multiple channels of the communication between the two systems, the noradrenergic sympathetic innervations of the lymphoid organs bear some of the requisite for the neural modulation of immunity. In addition to the presence of $\beta$ - and $\alpha$-adrenergic receptors on lymphocytes and other immunocompetent cells [1], anatomical studies have revealed the direct contact between tyrosine hydroxylase-positive nerve terminals

\footnotetext{
*Correspondence to: Dr. Toshihiko Katafuchi, Department of Integrative Physiology, Graduate School of Medical Sciences, Kyushu University, Fukuoka 812-8582, Japan. Tel: +81-92-6426087; Fax: +81-92-642-6093; E-mail: kataf@ physiol.med.kyushuu.ac.jp.
}

and lymphocytes in the spleen and thymus [2, 3]. However, the effects of noradrenaline (NA) on the immune responses in vitro are rather complicated depending on Th predominance, the timing of administration, and the dose of NA [4].

Natural killer (NK) cells serve as effectors of immunosurveillance against viral infection and tumor growth without any prior recognition with a specific antigen. Among the studies on neuronal modulation of immune functions, it seems that NK cells are liable to be influenced by the nervous system compared with other immune functions. Studies on human beings have demonstrated various life events such as bereavement [5] and academic examination [6], and depression or anxiety without coping [7] induce suppression of NK cell activity. A great number of animal experiments were performed to clarify the mechanisms of 
these phenomena. A possible role of the sympathetic NA innervations in the modulation of splenic NK cell activity, and its mechanisms in the hypothalamus are demonstrated in the present review. Furthermore, an involvement of brain cytokines and their actions on the sympathetic nervous system (SNS) in the immobilization (IMB) stress-induced suppression of splenic NK cell activity is discussed.

\section{SYMPATHETIC MODULATION OF SPLENIC NK CELL ACTIVITY}

Not only NK cells but also T lymphocytes/macrophages are known to have $\alpha_{2} / \beta_{2}$ adrenergic receptors. For example, effector function of cytotoxic $\mathrm{T}$ cells are suppressed by an increase in intracellular cAMP through $\beta_{2}$ adrenergic receptors [4]. In addition, following anti-CD3 activation, the $\beta_{2}$ adrenergic receptors were expressed on Th1 cells, but not Th2 cells, and interleukin-2 (IL-2) production was downregulated through the receptors [8]. Suppression of NK cell activity by $\beta$-adrenergic mechanisms was also proved by the following experiment [9]. The cytotoxicity of NK cells in the spleen was reduced 20 min after the laparotomy alone in anaesthetized rats. The reduced NK activity recovered significantly when the splenic nerve was cut immediately after the laparotomy. However, electrical stimulation $(0.5 \mathrm{~mA}$, $0.5 \mathrm{~ms}, 20 \mathrm{~Hz}$ for $20 \mathrm{~min}$ ) of the peripheral cut end of the nerve resulted in a further suppression of $\mathrm{NK}$ cytotoxicity, which was completely blocked by an intravenous injection of nadolol (a peripherally acting $\beta$-adrenergic receptor antagonist), but not by that of prazosin (an $\alpha$-antagonist). An in vitro study has shown that expression of perforin and granzyme $\mathrm{B}$, which are know to be cytotoxic proteins released by NK cells, is suppressed by NA and $\beta$-adrenergic agonist [10].

\section{HYPOTHALAMIC LESION/STIMULATION AND NK CELL ACTIVITY}

Classical method to assess the neuronal modulation of physiological responses is to investigate effects of stimulation/lesion of the discrete region of brain tissue on them. NK cell activity as well as T cell proliferation was suppressed by lesion of left hemisphere [11], medial septum [12], pineal body [13] and pituitary gland [14], while ablation of hippocampus results in an enhancement of Concanavalin A-induced mitogenic responses [15]. Changes in NK cell activity following hypothalamic nuclei have been also reported. Lesions of anterior hypothalamic area [16] and medial preoptic area (MPO) [17] induced suppression of splenic NK cell activity, and the latter was completely blocked by surgical splenic sympathectomy [17]. In addition, electrical lesion of the ventromedial hypothalamic nucleus (VMH), which is known to be a responsible site for hypothalamic obesity, results in suppression of splenic NK cell activity in acute phase and then the activity increases in chronic phase when the obesity is obvious [18]. On the other hand, electrical stimulation of the lateral hypothalamic area (LHA), one of the reward centers, produces an increase in NK cell activity [19].

\section{IMMUNOSUPPRESSION INDUCED BY BRAIN CYTOKINES}

Among proinflammatory cytokines, it has been shown that IL-1 $\beta$ and interferon- $\alpha$ (IFN- $\alpha$ ), but not TNF- $\alpha$ or IL-6, are known to suppress cellular immunity when injected into the brain. An intracerebroventricular (ICV) injection of IL-1 $\beta$ in rats suppresses various immune responses such NK cell activity, mitogenic response to phytohemagglutinin and IL-2 production of lymphocytes [20, 21], specific antibody production [22], and secretion of IL-1 from splenic macrophages [23]. The brain IL-1-induced suppression of cellular immunity was mediated by both the activation of hypothalamic-pituitary-adrenal (HPA) axis and the SNS, since chemical [21] and surgical [23] sympathectomy and adrenalectomy [20] only partially attenuated the immunosuppression.

ICV injection of IFN- $\alpha$ also resulted in the suppression of splenic NK cell activity [24]. Interestingly, the IFN- $\alpha$-induced suppression was blocked by ICV pretreatment with naloxone, an opioid antagonist. Since IFN- $\alpha$ inhibits naloxone binding to the brain membrane in rats, IFN- $\alpha$ may modulate certain physiological functions via opioid pathways in the brain [25]. The acting site of IFN- $\alpha$ is considered to be MPO, since microinjections of other brain regions such as hypothalamic paraventricular nucleus (PVN), VMH, LHA, hippocampus, amygdala, and central gray matter were not effective [26]. The suppressive effects of IFN- $\alpha$ administered ICV and into the MPO were both completely blocked by splenic sympathetic denervation $[24,26]$. Thus it is suggested that IFN- $\alpha$ reduces splenic NK cell activity exclusively by activating the SNS, while IL-1 $\beta$ does by both the HPA axis and SNS. As expected, an ICV injection of IFN- $\alpha$ [9] and IL-1 $\beta$ [27], or MPO injection of IFN- $\alpha$ [17] increased the electrical activity of the splenic sympathetic nerve. 


\section{AN INVOLVEMENT OF CORTICOTROPIN RELEASING FACTOR (CRF) AND PROSTAGLANDIN E (PGE $\left._{2}\right)$}

Both central IL-1 $\beta$ - and IFN- $\alpha$-induced suppressions of NK cell activity are completely blocked by pretreatment with anti-CRF antibody [21] and a CRF antagonist $\left(\alpha\right.$-helical $\left.\mathrm{CRF}_{9-41}\right)$ [24], respectively. In addition, the enhancement of the splenic sympathetic activity induced by ICV IL- $1 \beta$ was also blocked by $\alpha$-helical $\mathrm{CRF}_{9-41}$ [27]. An ICV injection of CRF decreased the splenic and blood NK cell activity [24, 28] and antibody production in rats [22]. The CRF-induced reduction of NK cell activity was completely blocked by ICV pretreatment with a ganglionic blocker, which also blocked an increase in plasma NA, whereas the same dose of the blocker did not affect the increase in plasma levels of ACTH and corticosterone [28]. These findings suggest that the SNS, but not the HPA axis, plays a significant role in the CRF-induced immunosuppression. Consistently, splenic sympathetic nerve activity [29] and NA release from splenic sympathetic nerve terminals [30] increased following ICV infusion of CRF in rats.

It has been shown that $\mathrm{PGE}_{2}$, which is a principal mediator of many proinflammatory cytokines, decreases proliferative responses of splenic lymphocytes by its action within the brain in rats [31]. Since this is accompanied by increase in plasma ACTH and corticosterone levels, it is likely that the activation of the HPA axis plays a role in this response. However, the splenic sympathetic nerve activity also increases after ICV infusion of $\mathrm{PGE}_{2}$ [29] through its action on EP1 receptor subtype for $\mathrm{PGE}_{2}$ [32]. Furthermore, an ICV injection of $\mathrm{PGE}_{2}$ but not that of $\mathrm{PGD}_{2}$ or $\mathrm{PGF}_{2 \mathrm{a}}$, increased the NA turnover in the spleen [33]. These data indicate that the SNS is also involved in the $\mathrm{PGE}_{2}$-induced immunosuppression. It has been shown that IL-1 $\beta$-induced ACTH release [34] and fever [35] are abolished by inhibition of a key enzyme of prostanoids syntheses (cyclooxygenase, COX). Similarly the enhancement of the splenic sympathetic activity [27] and the NA turnover in the spleen induced by central IL-1 $\beta$ [33] are also blocked by COX inhibitors. In addition, the IL- $1 \beta$-induced activation of splenic sympathetic nerve was blocked by pretreatment with I-melanocyte stimulation hormone $(\alpha-\mathrm{MSH})$ [27], which is known to reduce production of arachidonic acid, a substrate for prostanoids, by inhibiting phospholipase $A_{2}$. These findings suggest an involvement of prostanoid synthesis in the brain in the IL-1 $\beta$-induced reduction of cellular immunity.

As already mentioned, the ICV IL- $1 \beta$-induced enhancement of the splenic sympathetic activity was blocked by both a CRF antagonist and COX inhibitor [27]. An increase in the splenic nerve activity by ICV $\mathrm{PGE}_{2}$ was blocked by ICV pretreatment with $\alpha$-helical $\mathrm{CRF}_{9-41}$, a CRF antagonist, whereas the CRF-induced enhancement of the nerve activity was not affected by sodium salicylate, a COX inhibitor, at a dose 100 times more than that required for suppressing the IL$1 \beta$-induced activation of the nerve [29]. Therefore, it is possible that an activation of prostanoids-dependent process is followed by that of CRF system in the brain, resulting in the enhanced splenic nerve activity. A similar sequential relationship between prostanoidsdependent process and CRF mechanisms has been suggested in the IL-1-induced activation of the HPA axis [36].

\section{ROLES OF SPLENIC SYMPATHETIC NERVE IN STRESS-INDUCED IMMUNOSUPPRESSION}

Irwin et al. [37] have demonstrated that foot shock stress-induced reduction of splenic NK cell activity was mediated by brain corticotropin-releasing factor (CRF) independently to the activation of the HPA axis. It has been shown that foot shock-induced suppression of proliferative responses of splenocytes was blocked by surgical denervation of the splenic sympathetic nerve [38], suggesting that the sympathetic nerve may be a significant mediator of the immunosuppression. Shimizu et al. [39] have demonstrated that immobilization (IMB) for $90 \mathrm{~min}$ resulted in a reduction of the splenic NK cell activity in rats, and the suppression was attenuated by splenic denervation. They also showed that extracellular concentration of NA in the spleen measured by in vivo microdialysis in conscious rats markedly increased during IMB. Since the splenic denervation almost completely abolished the rise in NA levels, the increase in NA was due to the activation of splenic sympathetic nerve, but not derived from either other sympathetic nerve terminals or adrenal gland. Since an activation of splenic sympathetic nerve results in a suppression of splenic NK cell activity through a $\beta$-adrenergic receptor-mediated process [9], these findings, taken together, suggest that the stress-induced suppression of NK cell activity is mediated, at least partly, by the activation of the splenic sympathetic nerve. 


\section{HYPOTHALAMIC SITES INVOLVED IN THE SNS-MEDIATED IMMUNOSUPPRESSION}

Immediate early gene c-fos is commonly used as a marker for functionally activated neurons. After $90 \mathrm{~min}$ of IMB, Fos protein encoded by c-fos was found most heavily in the parvocellular region of the PVN and moderately in the LHA, VMH and MPO [40]. Neurons in the PVN are known to send axons not only to the median eminence but also to the brainstem and the spinal cord regulating the activity of the SNS. To observe influence of the IMB-induced Fospositive sites on splenic sympathetic nerve activity, an excitatory amino acid, glutamate, was administered in anesthetized rats. Microinjection of glutamate into the PVN and VMH enhanced the nerve activity, while the injection into the MPO and LHA decreased [17, 40]. These findings indicate that the PVN and VMH have an excitatory influence, while the MPO and LHA have an inhibitory influence on the splenic sympathetic nerve activity.

Since the PVN has an excitatory influence on splenic sympathetic nerve, it is possible that the activation of the PVN indicated by the Fos expression contributes to the suppression of the splenic NK cell activity following IMB. In addition, the MPO was also involved in the NK suppression, since the MPO was the only effective site in the hypothalamus following microinjection of IFN- $\alpha$ [26]. Since the MPO has an inhibitory influence on the splenic sympathetic nerve activity, it is not likely that IFN- $\alpha$ activates MPO neurons. In fact, IFN- $\alpha$ as well as IL- $1 \beta$, is demonstrated to reduce the firing rates of the MPO neurons [41], and a possible second mediator of IFN- $\alpha, \mathrm{PGE}_{2}$, also suppresses MPO neurons by activating $\mathrm{Ca}^{2+}$-activated $\mathrm{K}^{+}$ ion channels [42]. It is generally known that there is a direct projection from PVN to the sympathetic pregangalionic neurons in the lateral cell column of the spinal cord, but very few from the MPO. Therefore the MPO may modulate the sympathetic nerve activity through intrahypothalamic connections to the PVN. One possibility is that, since the MPO sends an inhibitory projection to the PVN [43], the suppression of the MPO neurons may disinhibit the PVN neuron activity, thereby inducing the enhancement of the nerve activity. In accordance with this, electrical lesion of the MPO resulted in the activation of the splenic sympathetic nerve activity and the suppression of the splenic NK cell activity, which was completely blocked by the denervation [17].

\section{INVOLVEMENT OF BRAIN CYTOKINES IN IMB-INDUCED IMMUNOSUPPRESSION}

It is well known that brain produces cytokines and possesses their receptors. Such cytokines are usually not found, or only are at very low levels, in the normal brain. The production of most cytokines is induced in glia such as astrocytes and microglia during pathological and inflammatory events in the brain; e.g., injury, ischemia, infection and degeneration [44]. Recently neuroinflammation induced by systemic administration of lipopolysaccharide (LPS) and polyinosinic:polycytidylic acid (poly I:C), which are ligands for toll-like receptor 4 and 3, respectively, has been extensively studied as a model for neurodegeneration, depression, and cognitive impairment [45-47]. Neuroinflammation is characterized by activation of glial cells and increased expression of cytokines and their related substances. Not only inflammatory insults but also non-inflammatory stress such as IMB has also shown to induce expression of IL- $1 \beta$ and IFN- $\alpha$ in the brain. In agreement with a previous finding by Northern blotting analysis [48], mRNAs for IFN- $\alpha$ and IL-1 $\beta$ were increased by IMB stress for $1 \mathrm{hr}$ in the rat in the MPO, VMH, LHA, and PVN as assessed quantitatively by real-time capillary RT-PCR [40].

The suppression of splenic NK cell activity induced by IMB in mice was blocked by pretreatment with antiIL- $1 \beta$ neutralizing antibody administered ICV $10 \mathrm{~min}$ before IMB, while the IMB-induced suppression was not affected by pretreatment with non-specific IgG (unpublished data). In addition, the reduction of lymphocyte proliferation induced by the foot-shock stress was also attenuated by ICV pretreatment with anti-IL-1 antibody [49]. These findings suggest that IL-1 $\beta$ produced in the brain during IMB is involved, at least in part, in the IMB-induced suppression of cellular immunity. Figure 1 shows a schematic illustration of the summary demonstrating involvement of stressinduced cytokines, $\mathrm{PGE}_{2}$ and $\mathrm{CRF}$ in hypothalamic modulation of splenic NK cell activity.

\section{CONCLUSION}

The network of the central nervous system consist of the afferent sensory, autonomic, and humoral pathways to receive external and internal information, and the efferent pathways to control the autonomic, endocrine, and homeostatic systems. Now we know that the immune system is also subsumed into this net- 


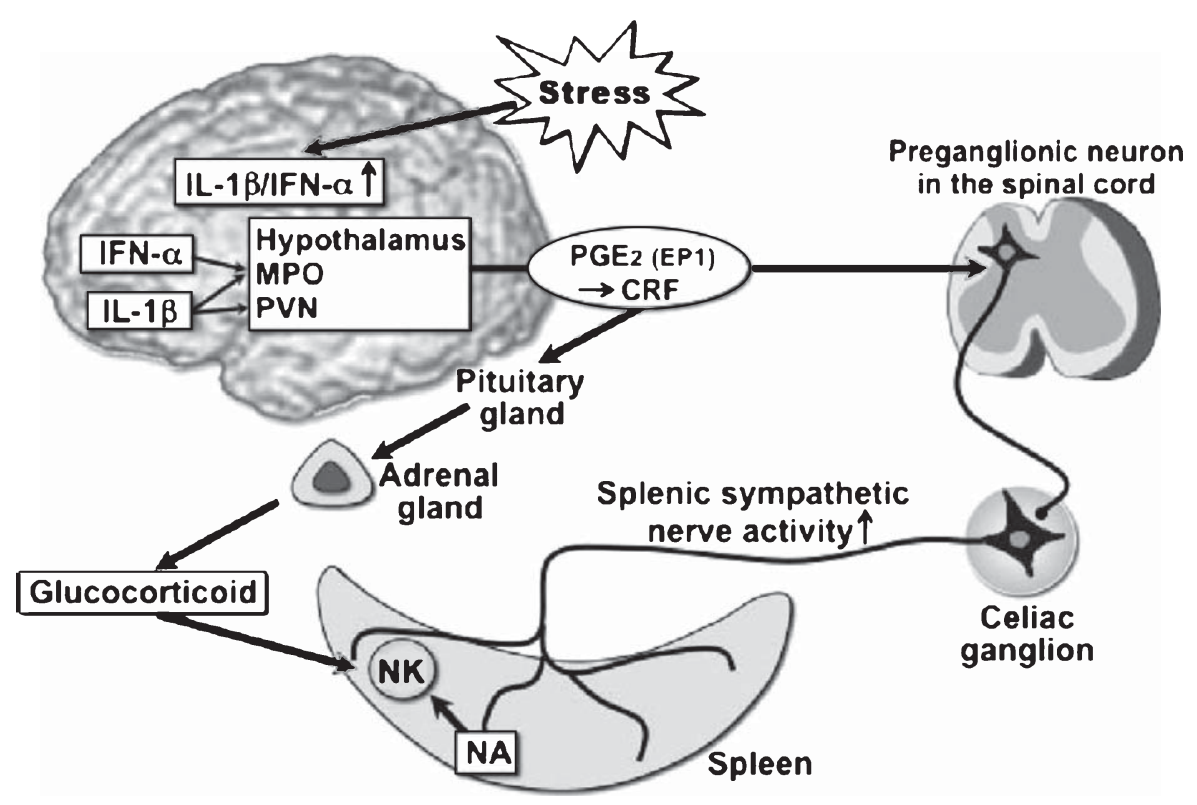

Fig. 1. Schematic illustration of hypothalamo-sympathetic/pituitary-adrenal modulation of splenic NK cell activity. Non-inflammatory stress induces IL-1 $\beta$ and IFN- $\alpha$ in the hypothalamus, which act on the MPO/PVN, resulting in the activation of splenic sympathetic nerve and the HPA axis through $\mathrm{PGE}_{2}$-EP1 receptor coupling and the following CRF activation, thereby suppressing splenic NK cell activity. IFN- $\alpha$ exclusively activates sympathetic nerve, while IL-1 $\beta$ does both sympathetic nerve and the HPA axis. In detail, see text. MPO, medial preoptic area; PVN, paraventricular nucleus; $\mathrm{PGE}_{2}$, prostaglandin $\mathrm{E}_{2}$; $\mathrm{CRF}$, corticotropin releasing factor; $\mathrm{NK}$, natural killer cell; NA, noradrenaline.

work thereby forming neuroimmune super system. In this system the hypothalamus plays an important role by integrating information of neuronal, endocrine and immune systems. The crosstalk in the neuroimmune super system contributes to the homeostatic/stress responses. Cytokines induced by non-inflammatory stress such as IMB in the hypothalamus act on neurons and glial cells, thereby influencing peripheral immune functions through the autonomic, endocrine, and homeostatic systems. It is concluded that the hypothalamo-sympathetic-immune network is one of the communication channels that mediate the central modulation of cellular immunity and this network is deeply involved in the immunomodulatory responses to stress including IMB-induced suppression of NK cell activity.

\section{REFERENCES}

[1] Sanders VM, Kasprowicz DJ, Kohm AP, Swanson MA. Neurotransmitter receptors on lymphocytes and other lymphoid cells. In, Ader R, Felten DL, Cohen N, editors. Psychoneuroimmunology third ed. San Diego: Academic Press; 2001. p. 161.

[2] Felten DL, Felten SY, Bellinger DL, Carlson SL, Ackerman $\mathrm{KD}$, Madden KS. et al. Noradrenergic sympathetic neural interactions with the immune system: structure and function. Immunol Rev. 1987; 100: 225.

[3] Bellinger DL, Lorton D, Lubahn C, Felten DL. Innervation of lymphoid organs-association of nerves with cells of the immune system and their implications in disease. In: Ader R, Felten DL, Cohen N, editors. Psychoneuroimmunology third ed. San Diego: Academic Press; 2001, 55.

[4] Madden KS, Livnat S. Catecholamine action and immunologic reactivity. In: Ader R, Felten DL, Cohen N, editors. Psychoneuroimmunology. third ed. San Diego: Academic Press; 2001. p. 283.

[5] Zisook S, Shuchter SR, Irwin M, Darko DF, Sledge P, Resovsky K. Bereavement, depression, and immune function. Psychiatry Res. 1994; 52(1): 1.

[6] Kiecolt-Glaser JK, Garner W, Speicher C, Penn GM, Holliday J, Glaser R. Psychosocial modifiers of immunocompetence in medical students. Psychosom Med. 1984; 46(1): 7.

[7] Locke SE, Kraus L, Leserman J, Hurst MW, Heisel JS, Williams RM. Life change stress, psychiatric symptoms, and natural killer cell activity. Psychosom Med. 1984; 46(5): 441.

[8] Ramer-Quinn DS, Baker RA, Sanders VM. Activated T helper 1 and $\mathrm{T}$ helper 2 cells differentially express the $\beta_{2}$ adrenergic receptor: a mechanism for selective modulation of T helper 1 cell cytokine production. J Immunol. 1997; 159(10): 4857.

[9] Katafuchi T, Take S, Hori T. Roles of sympathetic nervous system in the suppression of cytotoxicity of splenic natural killer cells in the rat. J Physiol. 1993; 465: 343.

[10] Dokur M, Boyadjieva N, Sarkar DK. Catecholaminergic control of NK cell cytolytic activity regulatory factors in the spleen. J Neuroimmunol. 2004; 151(1-2): 148. 
[11] Betancur C, Neveu PJ, Vitiello S, Lemoal M. Natural killer cell activity is associated with brain asymmetry in male mice. Brain Behavior and Immunity. 1991; 5(2): 162.

[12] Labeur M, Nahmod VE, Finkielman S, Arzt E. Lesions of the medial septal nucleus produce a long-lasting inhibition of T lymphocyte proliferation. Neurosci Lett. 1991; 125(2): 129 .

[13] del Gobbo V, Libri V, Villani N, Calio R, Nistico G. Pinealectomy inhibits interleukin-2 production and natural killer activity in mice. Int J Immunopharmacol. 1989; 11(5): 567.

[14] Saxena QB, Saxena RK, Adler WH. Regulation of natural killer activity in vivo. III. Effect of hypophysectomy and growth hormone treatment on the natural killer activity of the mouse spleen cell population. Int Arch Allergy Appl Immunol. 1982; 67(2): 169 .

[15] Cross RJ, Brooks WH, Roszman TL, Markesbery WR. Hypothalamic-immune interactions. Effect of hypophysectomy on neuroimmunomodulation. J Neurol Sci. 1982; 53(3): 557.

[16] Cross RJ, Markesbery WR, Brooks WH, Roszman TL. Hypothalamic-immune interactions: neuromodulation of natural killer activity by lesioning of the anterior hypothalamus. Immunology. 1984; 51(2): 399.

[17] Katafuchi T, Ichijo T, Take S, Hori T. Hypothalamic modulation of splenic natural killer cell activity in rats. J Physiol. 1993; 471: 209.

[18] Katafuchi T, Okada E, Take S, Hori T. The biphasic changes in splenic natural killer cell activity following ventromedial hypothalamic lesions in rats. Brain Res. 1994; 652(1): 164.

[19] Wenner M, Kawamura N, Miyazawa H, Ago Y, Ishikawa $\mathrm{T}$, Yamamoto H. Acute electrical stimulation of lateral hypothalamus increases natural killer cell activity in rats. J Neuroimmunol. 1996; 67(1): 67.

[20] Sundar SK, Becker KJ, Cierpial MA, Carpenter MD, Rankin LA, Fleener SL, et al. Intracerebroventricular infusion of interleukin 1 rapidly decreases peripheral cellular immune responses. Proc Natl Acad Sci U S A. 1989; 86(16): 6398.

[21] Sundar SK, Cierpial MA, Kilts C, Ritchie JC, Weiss JM. Brain IL-1-induced immunosuppression occurs through activation of both pituitary-adrenal axis and sympathetic nervous system by corticotropin-releasing factor. J Neurosci. 1990; 10(11): 3701.

[22] Irwin M. Brain corticotropin-releasing hormone- and interleukin-1 $\beta$-induced suppression of specific antibody production. Endocrinology. 1993; 133(3): 1352.

[23] Brown R, Li Z, Vriend CY, Nirula R, Janz L, Falk J, et al. Suppression of splenic macrophage interleukin-1 secretion following intracerebroventricular injection of interleukin- $1 \beta$ : evidence for pituitary-adrenal and sympathetic control. Cell Immunol. 1991; 132(1): 84.

[24] Take S, Mori T, Katafuchi T, Hori T. Central interferon $\alpha$ inhibits natural killer cytotoxicity through sympathetic innervation. Am J Physiol. 1993; 265 (2 Pt 2): R453.

[25] Menzies RA, Patel R, Hall NR, O'Grady MP, Rier SE. Human recombinant interferon $\alpha$ inhibits naloxone binding to rat brain membranes. Life Sci. 1992; 50(24): PL227.

[26] Take S, Uchimura D, Kanemitsu Y, Katafuchi T, Hori T. Interferon- $\alpha$ acts at the preoptic hypothalamus to reduce natural killer cytotoxicity in rats. Am J Physiol. 1995; 268(6 Pt 2): R1406.

[27] Ichijo T, Katafuchi T, Hori T. Central interleukin- $1 \beta$ enhances splenic sympathetic nerve activity in rats. Brain Res Bull. 1994; 34(6): 547.
[28] Irwin M, Hauger RL, Brown M, Britton KT. CRF activates autonomic nervous system and reduces natural killer cytotoxicity. Am J Physiol. 1988; 255(5 Pt 2): R744.

[29] Katafuchi T, Ichijo T, Hori T. Sequential relationship between actions of $\mathrm{CRF}$ and $\mathrm{PGE}_{2}$ in the brain on splenic sympathetic nerve activity in rats. J Auton Nerv Syst. 1997; 67(3): 200.

[30] Shimizu N, Hori T, Nakane H. An interleukin-1ß-induced noradrenaline release in the spleen is mediated by brain corticotropin-releasing factor: an in vivo microdialysis study in conscious rats. Brain Behav Immun. 1994; 8(1): 14.

[31] Rassnick S, Zhou D, Rabin BS. Central administration of prostaglandin $\mathrm{E}_{2}$ suppresses in vitro cellular immune responses. Am J Physiol. 1995; 269(1 Pt 2): R92.

[32] Ando T, Ichijo T, Katafuchi T, Hori T. Intracerebroventricular injection of prostaglandin $E_{2}$ increases splenic sympathetic nerve activity in rats. Am J Physiol. 1995; 269(3 Pt 2): R662.

[33] Terao A, Kitamura H, Asano A, Kobayashi M, Saito M. Roles of prostaglandins $\mathrm{D}_{2}$ and $\mathrm{E}_{2}$ in interleukin-1-induced activation of norepinephrine turnover in the brain and peripheral organs of rats. J Neurochem. 1995; 65(6): 2742.

[34] Katsuura G, Arimura A, Koves K, Gottschall PE. Involvement of organum vasculosum of lamina terminalis and preoptic area in interleukin 1 $\beta$-induced ACTH release. Am J Physiol. 1990; 258(1 Pt 1): E163.

[35] Stitt JT, Prostaglandin E as the neural mediator of the febrile response. Yale J Biol Med. 1986; 59(2): 137.

[36] Watanabe T, Morimoto A, Sakata Y, Murakami N. ACTH response induced by interleukin- 1 is mediated by CRF secretion stimulated by hypothalamic PGE. Experientia. 1990; 46(5): 481.

[37] Irwin M, Vale W, Rivier C. Central corticotropin-releasing factor mediates the suppressive effect of stress on natural killer cytotoxicity. Endocrinology. 1990; 126(6): 2837.

[38] Wan W, Vriend CY, Wetmore L, Gartner JG, Greenberg AH, Nance DM. The effects of stress on splenic immune function are mediated by the splenic nerve. Brain Res Bull. 1993; 30(12): 101.

[39] Shimizu N, Kaizuka Y, Hori T, Nakane H. Immobilization increases norepinephrine release and reduces NK cytotoxicity in spleen of conscious rat. Am J Physiol. 1996; 271(3 Pt 2): R537.

[40] Katafuchi T, Shi Z, Take S, Hori T. Hypothalamo-sympathetic control of cellular immunity. In: Nagatsu T, Nabeshima T, McCarthy R, Goldstein DS, editors. Catecholamine Research: from molecular insights to clinical medicine. New hyork: Kluwer Academic/Plenum Publishers; 2002. p. 277.

[41] Nakashima T, Hori T, Kuriyama K, Matsuda T. Effects of interferon- $\alpha$ on the activity of preoptic thermosensitive neurons in tissue slices. Brain Res. 1988; 454(1-2): 361.

[42] Katafuchi T, Duan S, Take S, Yoshimura M. Modulation of glutamate-induced outward current by prostaglandin $E_{2}$ in rat dissociated preoptic neurons. Brain Res. 2005; 1037(1-2): 180.

[43] Saphier D, Feldman S. Effects of stimulation of the preoptic area on hypothalamic paraventricular nucleus unit activity and corticosterone secretion in freely moving rats. Neuroendocrinology. 1986; 42(2): 167

[44] Hopkins SJ, Rothwell NJ. Cytokines and the nervous system. I: Expression and recognition. Trends Neurosci. 1995; 18(2): 83.

[45] Dantzer R, O'Connor JC, Freund GG, Johnson RW, Kelley KW. From inflammation to sickness and depression: when the immune system subjugates the brain. Nat Rev Neurosci. 2008; 9(1): 46. 
[46] Deleidi M, Hallett PJ, Koprich JB, Chung CY, Isacson O. The Toll-like receptor-3 agonist polyinosinic:polycytidylic acid triggers nigrostriatal dopaminergic degeneration. J Neurosci. 2010; 30(48): 16091.

[47] Lee JW, Lee YK, Yuk DY, Choi DY, Ban SB, Oh KW et al. Neuro-inflammation induced by lipopolysaccharide causes cognitive impairment through enhancement of beta-amyloid generation. J Neuroinflammation. 2008; 5: 37.
[48] Minami M, Kuraishi Y, Yamaguchi T, Nakai S, Hirai Y, Satoh M. Immobilization stress induces interleukin-1 $\beta$ mRNA in the rat hypothalamus. Neurosci Lett. 1991; 123(2): 254

[49] Saperstein A, Brand H, Audhya T, Nabriski D, Hutchinson $\mathrm{B}$, Rosenzweig $\mathrm{S}$, et al. Interleukin $1 \beta$ mediates stressinduced immunosuppression via corticotropin-releasing factor. Endocrinology. 1992; 130(1): 152 